\title{
Research on Laboratory Construction and Teaching Reform of Public Physical Education in Colleges and Universities at Internet + Era
}

\author{
Jianxue Liü ${ }^{1, \text { a }}$ \\ ${ }^{1}$ Department of Public Physical Education, Fuzhou University of International Studies and Trade, \\ Fuzhou, Fujian, China, 350202
}

\begin{abstract}
Keywords: Laboratory Construction, Teaching Reform, Public Physical Education, Colleges and Universities, Internet + Era
\end{abstract}

\begin{abstract}
The arrival of the Internet + era poses new challenges for the construction and teaching reform of public sports laboratories in colleges and universities. This paper discusses the management system, laboratory construction and the present situation of PE teaching in public colleges and universities, and analyzes the shortcomings of public sports laboratory construction and teacher teaching process. This paper puts forward the "three-in-one" sports practice teaching mode by constructing pre-class test student interest course, using information technology to assist teaching in class and real-time follow-up practice after class to provide new ideas for deepen the reform of public physical education and construct new public sports teaching system.
\end{abstract}

\section{Introduction}

The Internet + is the evolution of the Internet and the new forms of economic and social development. Internet + made with the Ministry of Education, the National College of Physical Education Instruction Outline - opened a new physical education reform. The quality and effect of public physical education are directly related to the enthusiasm of students in the study of physical education, which is related to the physical quality of students and the concept of sports after they enter the society. The physical education of public physical education is an important part of public physical education. The "knowledge and skills" of the Internet and the "process and method" of the "Outline" and the "emotions, attitudes and values" put forward new multidimensional goals for public physical education. However, public sports in the process of reform and development cannot be separated from the public sports laboratory hardware support. From the current point of view, many of our colleges and universities in the construction of public sports laboratories only to stay in the initial level of development, the concept of management is not enough to open up, management ideas are not enough innovation, it is difficult to meet the diverse needs of students sports.

\section{The Concept of "Internet +"}

In 2013, Tencent CEO Ma proposed the first "Internet +", it is the use of the Internet platform and the use of information and communication technology, including the Internet and traditional industries, including all walks of life together, in the new field to create a new Ecology. Premier Li Keqiang proposed in the government work report: the development of Internet + action plan to promote the mobile Internet, cloud computing, large data, Internet of things and modern manufacturing combined. The advent of the Internet + era affects the various fields and is no longer a simple business concept. The Ali Institute in the "Internet + research report" pointed out: the essence of Internet + is the traditional industry online, data. From the academic community has attracted the attention of scholars from all walks of life. It is in the Internet era to a certain stage of development, by the economic development mode, people's lifestyles and ideas, the emerging technology of the network and other factors together the results of a combination of various models, each area are Highly concerned about its impact, the current university education is generally considered the future of the Internet industry's most watched areas. 


\section{The Status Quo of Public Sports Laboratory Construction in Colleges and Universities}

At present, many domestic colleges and universities have been built to include sports room, physical fitness test room, rehabilitation health room, sports psychological training room, including public sports laboratory. The construction of the laboratory can basically complete the function of teaching and physical testing of ordinary students, but there are still many deficiencies. Specific performance: With the continuous expansion of the scale of college enrollment, public sports laboratory area and the proportion of the number of students is not the problem of increasingly prominent. Many colleges and universities on the public sports experimental equipment investment is not enough, outdated equipment, backward cannot meet the needs of students. The proportion of full-time experimental teachers in public sports laboratories in colleges and universities is too low to meet the teaching needs. Laboratory management system is not smooth, is not conducive to the development of public physical education.

\section{The Status Quo of Public Physical Education in Colleges and Universities}

Public college physical education is an important part of the public elective course that students are indispensable in the university stage, but the teaching situation is not optimistic. The concrete teaching mode is backward and it cannot stimulate students' interest in learning. Teaching materials outdated, the content of teaching from the student needs cannot cause students to resonate. The concept of teacher education is not enough innovation, lack of sense of the times, not good at teaching in the integration of fresh elements, boring, tedious explanation and low level of duplication led to the emergence of some college students "like sports and do not like physical education" strange.

\section{The Countermeasures to Improve the Public Sports Laboratory Construction and Teaching}

Rationalize the Public Sports Laboratory Management System. In order to give full play to the role of public sports laboratories, the school authorities should conduct extensive research, combined with the actual school to straighten out the public sports laboratory management system. Through the development of the rules and regulations, the establishment of the corresponding positions, a clear experimental director and experimental staff of the job responsibilities, clear the public sports laboratory tasks) through the development of appropriate rewards and punishments system, mobilize laboratory management, experimental teachers and experimental techniques The enthusiasm of the staff work, to maximize the creation of a good teaching and research atmosphere.

Actively Explore the "Three-In-One" Public Sports Practice Teaching Model. Internet + put forward, to the public sports laboratory construction made a lot of new requirements. In the Internet + era, if the university cannot learn from the development of modern technology to build a modern educational concept of public sports laboratories, then the public sports education will never be able to follow the pace of the times on the basis of science. Increase the construction of public sports laboratories, innovative construction concept, will greatly enhance the teaching effect of public sports.

In this way, the initial construction of the use of "sports laboratory" to find students interested in the course, with the virtual simulation center, micro-grid venues of advanced technology, combined with traditional teaching to do classroom teaching, after school full use of modern network and information technology Students after-school practice of tracking the pre-class test, class study, after-school practice "triple play" sports practice teaching mode.

Establish the College Students "Sports Laboratory". The 2014 Olympic Games held in Nanjing, Jiangsu Province, the International Olympic Committee President Bach advocated the establishment of the "sports laboratory" by the masses. As a new event of the Olympic Games, rock climbing, skating, martial arts, skateboarding and other projects in the master performances, and guide visitors to experience. Its experimental function is to test the non-traditional Olympic Games project for young athletes and spectators in the end with much attractive. Colleges and universities 
can also learn from this approach, through the establishment of "sports laboratory", in pre-class research and mining of contemporary college students interested in sports, and according to the statistical data appropriate increase, reduce the corresponding elective courses and the establishment of appropriate sports Places and facilities.

Establish and Improve the Public Sports Network Resources. With the help of MOOCs and the online learning platform, students can provide a wealth of learning resources such as sports skills, video analysis of all kinds of games, ballistic tactics teaching platform, sports aesthetic appreciation and other learning resources, the use of new computer-aided teaching and flip teaching and other methods to enrich the public the teaching of sports, to stimulate students' interest in learning; invested in the development of public sports mobile APP, and installed to the teachers and students of the client, for physical test data analysis, real-time records and assessment of students to participate in sports activities. The arrival of large data age can abandon the past information island phenomenon, so that teachers through advanced information technology to keep abreast of the effect of students

Establish the Virtual Simulation Center for Sports Skill Teaching. According to the requirements of the construction of the virtual simulation center proposed by the Ministry of Education, the author puts forward the problem of restricting the time, space and speed of the teachers in the teaching of sports skill. By setting up the virtual simulation center with the combination of information technology will explain the sports skills to do the detailed action decomposition, in the form of virtual simulation to fundamentally overcome the drawbacks of the traditional teaching model, the scientific control of the entire sports skills teaching process to maximize the effectiveness of public physical education.

There are some good conditions such as gymnastics room, gym and other sports venues installed in the mirror, allowing students to learn the action, master the skills through the mirror to try to figure out the action, but in foreign countries, the use of computer simulation technology to move the laboratory to the stadium, it is very common and effective to monitor the student's action skills teaching process. We can also create a sports micro-course, through the information technology in the class of students to master the sports activities of the technical action in real time analysis and diagnosis to help students quickly and comprehensively master the professional skills.

Make full use of the current network and information technology for the students physical, physical data collection, transmission, analysis and processing solutions to provide technical support, modern wearable equipment to take full advantage of sensor technology, you can easily pick up the body of the body such as body weight, sleep, heartbeat, blood pressure, etc.) can be easily transmitted remotely to facilitate the storage and analysis of data, these technologies make learning and exercise from the qualitative to quantitative as possible, both the construction of the laboratory and both teachers and students should be able to adapt to this development, students can according to their actual situation to develop learning and training programs to achieve the best state of the body, and this scientific ideas and methods will enable students to pay attention to income, rather than the traditional way of exercise, the teacher can according to the needs of the curriculum, at any time to see the students after school exercises to remind students to actively participate in sports.

Teachers can also make full use of the Internet + times of the various favorable conditions for the current adolescents in the physical problems, such as overweight, myopia, three high age, etc.) to effectively solve the improvement of the national physical and practical It is necessary to strengthen the construction of public PE teachers to improve the quality of public physical education, to improve the enthusiasm of students, improve physical fitness and constantly strengthen the construction of public physical education teachers. According to the characteristics of public physical education teachers and professional teachers, research requirements and educational objects of different characteristics, the development of the corresponding title promotion, performance appraisal regulations, to fully mobilize the enthusiasm of teachers, change a lot of public The status quo of low education and low title of PE teachers. We plan to organize young people to study, study and undertake high-level research projects, pay attention to the echelon 
construction of public physical education teaching talents, focus on cultivating young teachers with potential, and actively create favorable environment and conditions for talent cultivation, increase talent introduction Efforts to focus on the introduction of innovative talents of the complex, in order to meet the requirements of the development of the times to introduce both proficient in sports and proficient in information technology talent, requiring the new era of public physical education teachers can not only do teaching work, but also competent experimental teaching and scientific research work, pay attention to the activities of the teaching and research section, carefully organize the activities of the weekly teaching and research section, public physical education teachers can really use the activities of the teaching and research section to discuss and learn how to use the new teaching facilities and exchange teaching experience, joint discussion of teaching assist software production and use, only by improving the overall teaching level of public physical education teachers in order to improve the quality of teaching.

\section{Conclusion}

The Internet + era has provided a good platform for the reform of public sports laboratory and put forward new requirements for the construction of public physical education teachers. Only by accelerating the construction of new public sports teaching system can we promote the healthy development of professional disciplines, courses, teaching and learning activities. In order to continuously improve the enthusiasm and sports skills of college students, they should learn sports appreciation and gradually develop the habit of life-long sports.

\section{References}

[1] Gao Jun, Fu Yanmin. College sports laboratory construction and experimental teaching reform[J] . Laboratory Research and Exploration, 2009, 16(3): 62-67.

[2] Zhang Hui. Analysis on the Reform of Public Physical Education in Colleges and Universities[J]. Education and Teaching Forum, 2011, 12(7): 23-28.

[3] Zheng Jianmin. Chinese and American colleges and universities in public physical education teaching assessment of the proportion of cases[J]. Journal of Physical Education, 2014, 8(3): $72-77$.

[4] Guan Shuo. University of sunshine sports to carry out the status quo and strategy[J]. Huangjiang Higher Education Research, 2014, 6(4): 52-58.

[5] Zhang Qiong. Reflections on the teaching reform of public physical education in ordinary colleges and universities[J]. Chinese Journal of Kunming University, 2011, 11(3): 55-58. 